\title{
Correction to: Democracy and Economic Growth: a Literature Review
}

\author{
Wafa Ghardallou ${ }^{1,2} \cdot$ Dorsaf Sridi $^{3}$
}

Accepted: 22 December 2021 / Published online: 12 February 2022

(c) Springer Science+Business Media, LLC, part of Springer Nature 2022

\section{Correction to: Journal of the Knowledge Economy (2020) 11:982-1002 https://doi.org/10.1007/s13132-019-00594-4}

The original version of this article, published on 12 February 2019, needs modification on authors' updated affiliation. This is as per authors' preference. Updated affiliations are reflected below.

${ }^{1}$ Department of Accounting, College of Business Administration, Princess Nourah bint Abdulrahman University, Riyadh, Saudi Arabia.

${ }^{2}$ Orleans Economics Laboratory (LEO), University of Orleans, UMR CNRS 7322 Rue de Blois, BP 26739, 45067 Orléans Cedex 2, France.

${ }^{3}$ Faculty of Economic Sciences and Management (FSEG), University of Sousse, B.P. 307, Cité Erriadh, 4023 Sousse, Tunisia.

The original article has been corrected.

Acknowledgements This research was funded by the Deanship of Scientific Research at Princess Nourah bint Abdulrahman University through the Fast-track Research Funding Program.

Publisher's Note Springer Nature remains neutral with regard to jurisdictional claims in published maps and institutional affiliations.

The original article can be found online at https://doi.org/10.1007/s13132-019-00594-4.

Wafa Ghardallou

wafa.ghardallou@gmail.com; wrghadoallou@pnu.edu.sa

1 Department of Accounting, College of Business Administration, Princess Nourah bint Abdulrahman University, Riyadh, Saudi Arabia

2 Orleans Economics Laboratory (LEO), University of Orleans, UMR CNRS 7322 Rue de Blois, BP 26739, 45067, Orléans Cedex 2, France

3 Faculty of Economic Sciences and Management (FSEG), University of Sousse, B.P. 307, Cité Erriadh, 4023 Sousse, Tunisia 